NEXT Ion Propulsion System Development Status and Performance

Michael J. Patterson and Scott W. Benson

Glenn Research Center, Cleveland, Ohio 


\section{NASA STI Program . . . in Profile}

Since its founding, NASA has been dedicated to the advancement of aeronautics and space science. The NASA Scientific and Technical Information (STI) program plays a key part in helping NASA maintain this important role.

The NASA STI Program operates under the auspices of the Agency Chief Information Officer. It collects, organizes, provides for archiving, and disseminates NASA's STI. The NASA STI program provides access to the NASA Aeronautics and Space Database and its public interface, the NASA Technical Reports Server, thus providing one of the largest collections of aeronautical and space science STI in the world. Results are published in both non-NASA channels and by NASA in the NASA STI Report Series, which includes the following report types:

- TECHNICAL PUBLICATION. Reports of completed research or a major significant phase of research that present the results of NASA programs and include extensive data or theoretical analysis. Includes compilations of significant scientific and technical data and information deemed to be of continuing reference value. NASA counterpart of peer-reviewed formal professional papers but has less stringent limitations on manuscript length and extent of graphic presentations.

- TECHNICAL MEMORANDUM. Scientific and technical findings that are preliminary or of specialized interest, e.g., quick release reports, working papers, and bibliographies that contain minimal annotation. Does not contain extensive analysis.

- CONTRACTOR REPORT. Scientific and technical findings by NASA-sponsored contractors and grantees.
- CONFERENCE PUBLICATION. Collected papers from scientific and technical conferences, symposia, seminars, or other meetings sponsored or cosponsored by NASA.

- SPECIAL PUBLICATION. Scientific, technical, or historical information from NASA programs, projects, and missions, often concerned with subjects having substantial public interest.

- TECHNICAL TRANSLATION. Englishlanguage translations of foreign scientific and technical material pertinent to NASA's mission.

Specialized services also include creating custom thesauri, building customized databases, organizing and publishing research results.

For more information about the NASA STI program, see the following:

- Access the NASA STI program home page at http://www.sti.nasa.gov

- E-mail your question via the Internet to help@sti.nasa.gov

- Fax your question to the NASA STI Help Desk at 301-621-0134

- Telephone the NASA STI Help Desk at 301-621-0390

- Write to: NASA Center for AeroSpace Information (CASI) 7115 Standard Drive Hanover, MD 21076-1320 
NASA/TM-2008-214986

AIAA-2007-5199

\section{NEXT Ion Propulsion System Development Status and Performance}

Michael J. Patterson and Scott W. Benson

Glenn Research Center, Cleveland, Ohio

Prepared for the

43rd Joint Propulsion Conference

sponsored by the American Institute of Aeronautics and Astronautics

Cincinnati, Ohio, July 8-11, 2007

National Aeronautics and

Space Administration

Glenn Research Center

Cleveland, Ohio 44135 
Level of Review: This material has been technically reviewed by technical management.

Available from

NASA Center for Aerospace Information

7115 Standard Drive

Hanover, MD 21076-1320
National Technical Information Service 5285 Port Royal Road Springfield, VA 22161

Available electronically at http://gltrs.grc.nasa.gov 


\title{
NEXT Ion Propulsion System Development Status and Performance
}

\author{
Michael J. Patterson and Scott W. Benson \\ National Aeronautics and Space Administration \\ Glenn Research Center \\ Cleveland, Ohio 44135
}

\begin{abstract}
NASA's Evolutionary Xenon Thruster (NEXT) project is developing next generation ion propulsion technologies to provide future NASA science missions with enhanced mission performance benefit at a low total development cost. The objective of the NEXT project is to advance next generation ion propulsion technology by producing engineering model and prototype model system components, validating these through qualification-level and integrated system testing, and ensuring preparedness for transitioning to flight system development. This paper describes the NEXT ion propulsion system development status, characteristics and performance. A review of mission analyses results conducted to date using the NEXT system is also provided.
\end{abstract}

\section{Nomenclature}

BOL Beginning-of-Life

DCIU Digital Control Interface Unit

EGA Earth Gravity Assist

EM Engineering Model

$F \quad$ Thrust, $\mathrm{mN}$

FCD Flow Control Device

GRC Glenn Research Center

HPA High Pressure Assembly

JPL Jet Propulsion Laboratory

I Thruster total impulse, Newton seconds

$I_{b} \quad$ Beam current, Amperes

IPS Ion Propulsion System

$I_{s p} \quad$ Specific impulse, $\mathrm{s}$

JPA Jupiter Gravity Assist

LPA Low Pressure Assembly

$L_{t} \quad$ Projected thruster life time, $\mathrm{khr}$

$M_{T} \quad$ Mass flow rate into thruster, $\mathrm{mg} / \mathrm{s}$

$M_{\text {T-TOT }}$ Thruster total propellant throughput capability, kg of Xenon

NEXT NASA's Evolutionary Xenon Thruster project

NSTAR NASA Solar Electric Propulsion Technology Application Readiness

PFCV Proportional Flow Control Valve

$P_{i n-P P U} \quad$ PPU input power, $\mathrm{kW}$ (unless otherwise specified)

$P_{i n-t} \quad$ Thruster input power, $\mathrm{kW}$ (unless otherwise specified)

PM Prototype Model

PMS Propellant Management System

PPU Power Processor Unit

TRL Technology Readiness Level

$V_{b p s} \quad$ Beam power supply voltage, Volts

$\eta_{P P U} \quad$ Demonstrated PPU efficiency (breadboard, at $100 \mathrm{~V}$ input bus voltage)

$\eta_{t} \quad$ Demonstrated Thruster efficiency (PM)

$\eta_{\text {System }} \quad$ System efficiency, product of thruster and PPU efficiencies 


\section{Introduction}

The NASA Glenn Research Center (GRC) is responsible for the development of NEXT ion propulsion system (IPS). ${ }^{1}$ The objective of the NEXT project is to advance next generation ion propulsion technology to NASA Technology Readiness Level (TRL) 6. This two-phase project is sponsored by NASA Science Mission Directorate (SMD), conducted under the In-Space Propulsion Technology Program (ISPT). NEXT was implemented through a competitively-

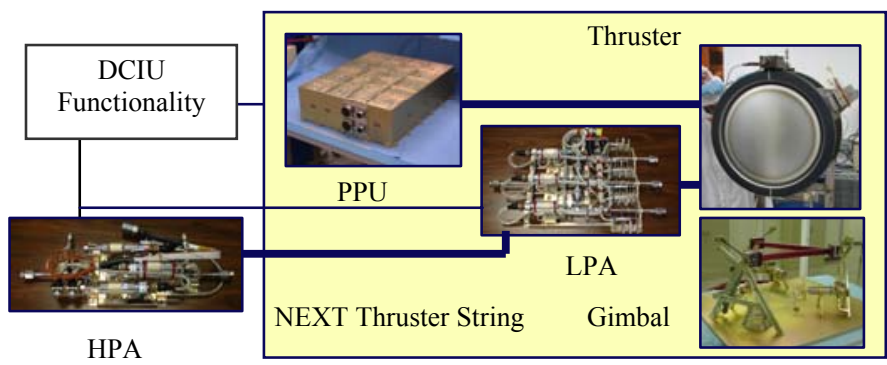

Figure 1.-NEXT Ion Propulsion System Elements. selected NASA Research Announcement awarded in 2002 with the first phase completed in August 2003. Technology validation and mission analysis results in Phase 1 indicated that the NEXT technologies have the capabilities that provide the expected benefits, and further development was warranted (ref. 1). The second phase of the project was initiated in October 2003 and continues.

The NEXT system elements (depicted in fig. 1) consist of a high performance, 7-kW, ion thruster; a modular, high-efficiency 7-kW power processor unit (PPU); a highly flexible advanced xenon propellant management system (PMS) consisting of a single High Pressure Assembly (HPA) and one Low Pressure Assembly (LPA) per thruster; a lightweight engine gimbal; and key elements of a digital control interface unit (DCIU) including software algorithms (refs. 2 to 5). This design approach was selected to provide future NASA science missions with the greatest value in mission performance benefit at a low total development cost.

The NEXT thruster and other component technologies represent a significant advancement in technology beyond state-of-the-art (SOA) NSTAR thruster systems (refs. 1 and 6). NEXT performance exceeds single or multiple NSTAR thrusters over most of the thruster input power range. Higher efficiency and specific impulse, and lower specific mass reduce the wet propulsion system mass and parts count. The NEXT thruster xenon propellant throughput capability is more than twice NSTAR's, so fewer thrusters are needed. The NEXT power processor and propellant feed system technologies provide mass and performance benefits versus NSTAR. Comparisons of NEXT SOA NSTAR performance characteristics are listed in table 1. The NEXT IPS development project has also placed particular emphasis on key aspects of IPS development with the intention of avoiding the difficulties experienced by the Dawn mission in transitioning the NSTAR-based technology to an operational ion propulsion system (ref. 7). These aspects are discussed in more detail later.

TABLE 1.-PERFORMANCE CHARACTERISTICS OF NEXT VERSUS NSTAR SOA

\begin{tabular}{|l|c|c|}
\hline \multicolumn{1}{|c|}{ Characteristic } & NEXT & NSTAR SOA \\
\hline Thruster Power Range, $\mathrm{kW}$ & $0.5-6.9$ & $0.5-2.3$ \\
\hline Max. Specific Impulse, $\mathrm{s}$ & $>4100$ & $>3100$ \\
\hline Max. Thrust, $\mathrm{mN}$ & 236 & 92 \\
\hline Max. Thruster Efficiency & $>70 \%$ & $>61 \%$ \\
\hline Max. PPU Efficiency & $95 \%$ & $92 \%$ \\
\hline PPU Specific Mass, $\mathrm{kg} / \mathrm{kW}$ & 4.8 & 6.0 \\
\hline PMS Single-String Mass, kg & 5.0 & 11.4 \\
\hline PMS Unusable Propellant Residual & $1.00 \%$ & $2.40 \%$ \\
\hline
\end{tabular}

\footnotetext{
${ }^{1}$ The NEXT team consists of NASA GRC as technology project lead, JPL as system integration lead, Aerojet (Redmond, WA) as PM thruster, PMS, and DCIU simulator developer, and L3 Comm ETI (Torrance, CA) as PPU developer.
} 


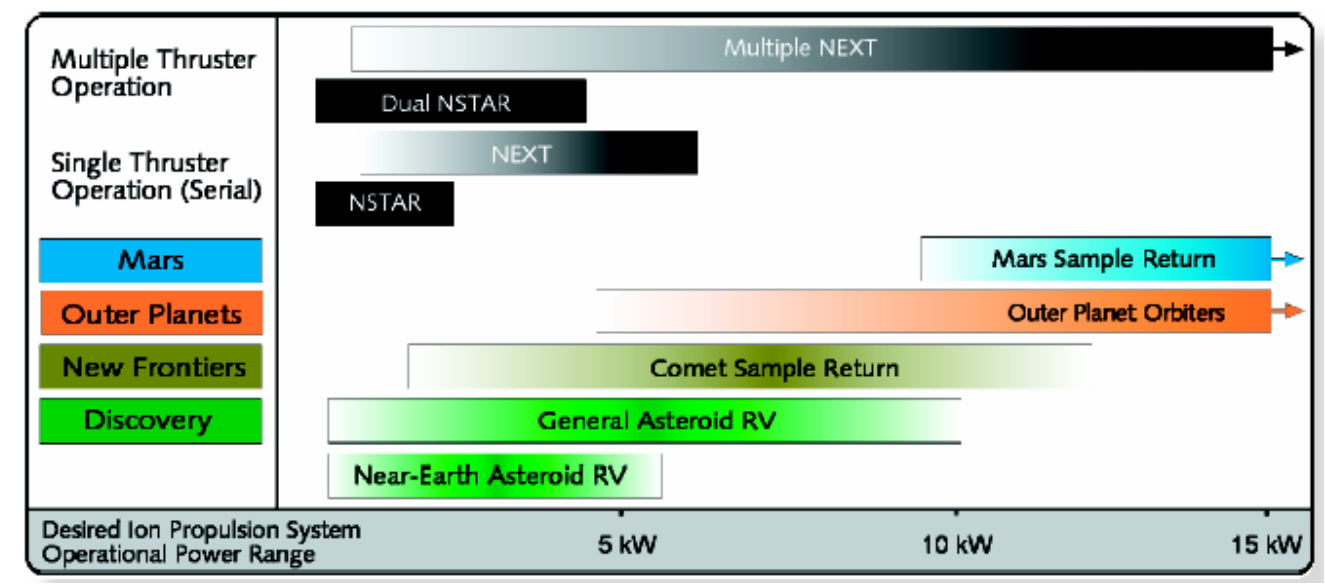

Figure 2.-NEXT makes high-performing ion propulsion systems available to a wide range of NASA missions.

NEXT technology is applicable to a wide range of NASA solar system exploration missions (see fig. 2), as well as earth-space commercial and other missions of national interest. NEXT affords larger delivered payloads and smaller launch vehicle size for Discovery, New Frontiers, Mars Exploration, and Flagship outer-planet exploration missions.

\section{Development Status}

This section summarizes project activities conducted during Phase 1 and Phase 2 relative to subsystem and system elements, and the present and intended development status of the elements at Phase 2 completion.

\section{A. Thruster}

The NEXT thruster is a 0.54 to $6.9 \mathrm{~kW}$ input power, $36 \mathrm{~cm}$ beam diameter, xenon ion thruster with 2-grid ion optics. The beam current at full power of $6.9 \mathrm{~kW}$ is $3.52 \mathrm{~A}$. It has a maximum specific impulse of greater than $4170 \mathrm{~s}$ at a maximum thrust of greater than $236 \mathrm{mN}$, with a peak efficiency in excess of $70 \%$. The xenon throughput project requirement is $>300 \mathrm{~kg}\left(1.23 \times 10^{7} \mathrm{~N}\right.$-s total impulse), with a $450 \mathrm{~kg}$ qualification level. The analysis-based capability of the thruster is $>730 \mathrm{~kg}$.

Five engineering model (EM) thrusters have been manufactured at GRC and tested. During Phase 1 of the NEXT project (ending in August 2003) EM thruster testing included detailed performance evaluations (ref. 8), a $2000 \mathrm{hr}$ wear test at full power (ref. 9), integration testing with a breadboard PPU and breadboard PMS (ref. 10) and structural tests to characterize thruster dynamic behavior for further thruster development (ref. 11). During Phase 2 to date, EM thruster performance has been tested in a multi-thruster array (ref. 12), and a long-duration life test of an EM thruster has accumulated more than $9200 \mathrm{hr}$ of operation at full power.

Also during Phase 2 the first prototype model $^{2}$ (PM) thruster was manufactured by Aerojet and delivered to GRC in January 2006. Acceptance testing of the thruster was completed at GRC and the performance was found to be consistent with that demonstrated from multiple EM thrusters. The PM thruster was subsequently subjected to a series of validation tests at JPL including: thruster/gimbal functional tests, a thermal development test, and qualification-level environmental (vibration and thermal vacuum) tests. The thermal development test proceeding environmental tests was performed to develop

\footnotetext{
${ }^{2}$ The PM thruster incorporates flight-level design and fabrication processes. The thruster mass is $12.7 \mathrm{~kg}$ (13.5 kg with cable harness).
} 
and validate the thruster thermal model and demonstrate thruster operation and temperature margins over a large temperature range. The vibration test was conducted with the PM thruster integrated with the gimbal; conditions were $10.0 \mathrm{G}_{\mathrm{rms}}$, through each of the 3 axes for 2-min duration. The thruster performance was nominal pre- and post-vibration.

Thermal vacuum testing of the PM thruster was conducted using flight-approved methods and the Dawn spacecraft environmental requirements and test procedures (see fig. 3). Test parameters included $-120{ }^{\circ} \mathrm{C}$ cold and $203{ }^{\circ} \mathrm{C}$ hot limits, and 3 cycles with hot and cold dwells, with hot and cold thruster starts. Testing was truncated during the 3rd cold cycle due to minor damage incurred during prior vibration testing. Functional testing of the thruster was subsequently completed with all data nominal. The PM thruster is presently undergoing minor rework at Aerojet in preparation for system integration testing at GRC and a second round of qualification-level environmental testing at JPL. The thruster will then be incorporated into the life validation program upon completion of testing.

Manufacturing of components for a second PM thruster

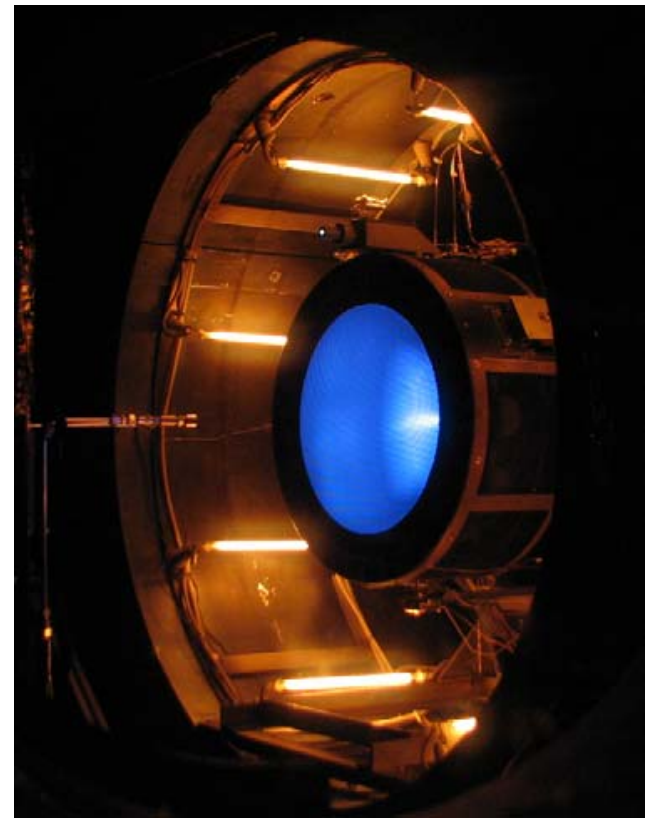

Figure 3.-PM Thruster undergoing Thermal Vacuum Testing at JPL. have been completed at Aerojet and are available for assembly in support of 1st-user needs; e.g.,- - qualification unit thruster. Thruster documentation (work instructions and drawings) will be formally released under the contractor configuration management process prior to assembly of the second PM thruster.

\section{B. Power Processor Unit}

Manufacturing of an engineering model (EM) PPU is nearing completion at L3 Comm ETI (L3) (fig. 4). ${ }^{3}$ This was preceded by fabrication and successful integration test of breadboard PPU during Phase 1. The PPU is planned to be delivered to GRC for thruster integration testing and then qualificationlevel vibration and thermal vacuum testing back at L3. The PPU will subsequently be used in systems integration testing which will include EMI/EMC measurements.

The PPU incorporates a modular beam power supply and improved packaging that provides performance and produce-ability benefits over the NSTAR PPU approach. It has a flexible, scalable

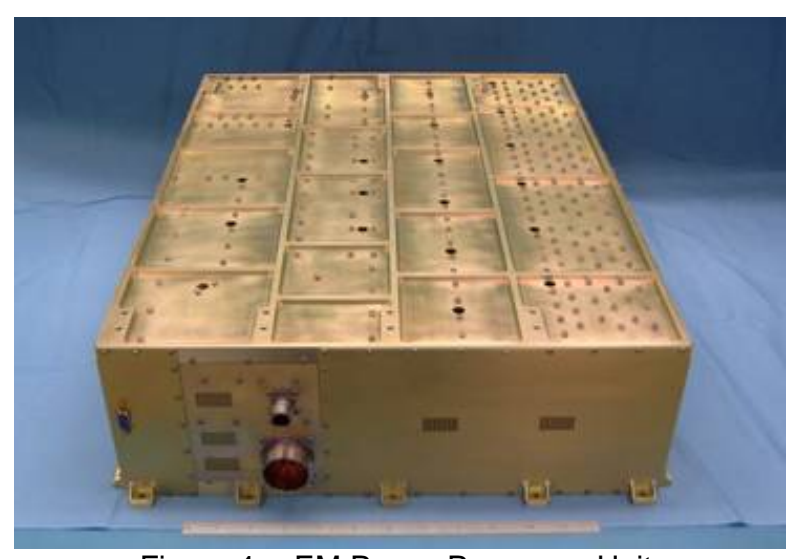

Figure 4.-EM Power Processor Unit. architecture which can be adapted to a wide range of thrusters ${ }^{4}$ and missions, with a wide throttle range capability $\left(250\right.$ to $7200 \mathrm{~W}$ ), a $>0.2 \mathrm{~kW} / \mathrm{kg}$ specific power, and a simple thermal interface (a $65{ }^{\circ} \mathrm{C}$ baseplate).

\footnotetext{
${ }^{3}$ The PPU design was fully documented prior to manufacturing with all drawings and assembly instructions in place and under configuration management prior to fabrication.

${ }^{4}$ The NEXT PPU is fully-compatible with operating the NSTAR thruster over its full throttle table; this was successfully demonstrated using the NEXT breadboard PPU on an EM NSTAR thruster.
} 
Additional design elements of the PPU include the following features described below. The PPU has modular construction designed for manufacturability and low cost. The input is designed for a wide range unregulated input bus ( 80 to $160 \mathrm{Vdc}$ ), with separate 100 and $28 \mathrm{~V}$ input filters. The balanced filters conform to JPL requirements (isolated return). The PPU has separate thruster outputs capable of operating two thrusters, one at a time. It also is designed to accommodate independent neutralizer keeper operation so that the PPU can operate the beam of one thruster combined with the neutralizer from a second thruster. The PPU has a built-in grid clear circuit with variable programmable duration and current capability up to the full output current of the discharge power supply (ref. 3).

\section{Propellant Management System}

The EM Propellant Management System (PMS) (fig. 5) delivers low pressure gas to the thruster from a supercritical xenon supply source, and it consists of HPA and LPA (ref. 14). The PMS provides independent xenon flow control to the thruster main discharge, and discharge and neutralizer cathodes. Xenon flow control is achieved by use of a thermal throttle flow control device (FCD) and a proportional flow control valve (PFCV). The FCD is a porous metal plug which provides a desired flow rate for a given inlet pressure and operating temperature. Fine control of flow rate is achieved by precise, active control of the FCD inlet pressure while the operating temperature of the porous metal plug is controlled at a constant setpoint. The inlet pressure and operating temperature of the FCD are actively controlled by the DCIU simulator. The inlet pressure is controlled using the PFCV with pressure transducer signal feedback while the operating temperature is controlled using a resistive element heater and temperature sensor feedback signal. This NEXT PMS design concept (ref. 13) provides significant mass and volume reductions in the system as compared to the bang-bang regulation scheme implemented for the Deep Space 1 and Dawn missions (ref. 14). ${ }^{5}$

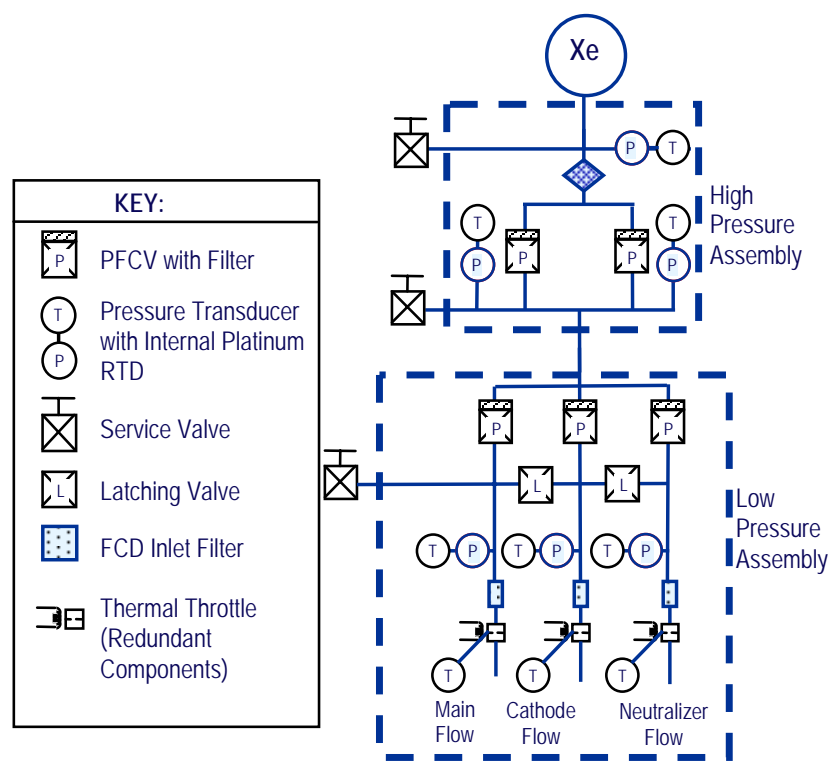

Figure 5.- Schematic of NEXT EM Propellant Management System.

\footnotetext{
${ }^{5}$ The NEXT PMS is fully-compatible with the NSTAR thruster, operable over its entire throttling table with greater flow precision and independent flow control of all 3 feeds to the thruster.
} 
Aerojet has completed manufacturing of the EM PMS elements, including 2 HPAs (one flight-like) and 3 LPAs (one-flight like). ${ }^{6}$ All assemblies have completed functional testing, and both flight-like HPA and LPA assemblies have successfully completed qualification-level vibration testing $\left(14.10 \mathrm{G}_{\mathrm{rms}}\right.$ through each of the 3 axes for 2 min duration) (ref. 13) and thermal vacuum testing (four thermal cycles from 12 to $70{ }^{\circ} \mathrm{C}$ ). The assemblies have been delivered to GRC and are being prepared for system integration testing.

\section{Digital Control Interface Unit}

The Digital Control Interface Unit (DCIU) is the primary interface between the spacecraft and the ion propulsion system. It performs all the command and control functions for the PMS and the PPU. Under the scope of the NEXT program only DCIU simulators have been developed. The DCIU simulator consists of a computer, test support equipment, EM PMS pressure loop control cards, and the associated algorithms to control the PMS and PPU. The DCIU simulators are capable of operating a 3 thruster string system, and are being used to validate control algorithms, support PPU input/output testing and singlestring and multi-string integration tests, and operate a PMS kernel during thruster life testing. Fully integrating the DCIU functionality into the PPU is under consideration as an approach that may be implemented in a follow-on PPU build cycle. Elimination of the separate DCIU should reduce system cost and complexity.

\section{E. Gimbal}

JPL has completed the development of a breadboard gimbal for the NEXT thruster (ref. 15). Designed and fabricated by Swales Aerospace, the gimbal is of a flight-like design using JPL-approved materials with certifications. The mass of the gimbal is less than $6 \mathrm{~kg}$ (lighter than the Dawn gimbal used for the smaller NSTAR thruster), and has a two-axis range of motion: $\pm 19^{\circ}, \pm 17^{\circ}$. The gimbal has successfully completed integration and functional testing with the PM thruster (fig. 6), and has passed two qualification level vibration tests and low-level shock tests, with minor issues. Few if any modifications are anticipated to transition to flight. However torque margin tests with the thruster harness and propellant line routing attached will be required.

\section{F. System Integration}

Single string integration testing was conducted in Phase 1 (ref. 10). This test included an EM thruster with a breadboard PPU and breadboard PMS. Early in Phase 2 a multi-thruster array test (MTAT) was executed at GRC, focusing on the characterization of individual thruster, and array, performance and behavior - as affected by the simultaneous operation of multiple ion thrusters (ref. 12). The subject of this effort was a four engineering model NEXT thruster array in a 3+1 flight-representative configuration where one thruster was dormant (a spare) (see fig. 7). This test was executed concurrent with detailed plasma environments and plume measurements (refs. 16 to 19). The array was operated over a broad range of conditions including the simultaneous firing of 3 thrusters at $20.6 \mathrm{~kW}$ total input power, yielding a total thrust of about $710 \mathrm{mN}$, at $4190 \mathrm{~s}$ specific impulse and approximately $71 \%$ efficiency. Major findings from the MTAT include: the performance observed for a thruster during operation in an array configuration appears to be consistent with that measured during singular thruster operation with no apparent deleterious interactions; and, operation of 1 neutralizer to neutralize 2-or-more thruster beams appears to be a potentially viable fault-recovery mode, and viable system architecture with significant system performance advantages. Overall, the results indicated single thruster operations are generally

\footnotetext{
${ }^{6}$ The non-flight like assemblies are identical except for the use of lower cost equivalent parts.
} 


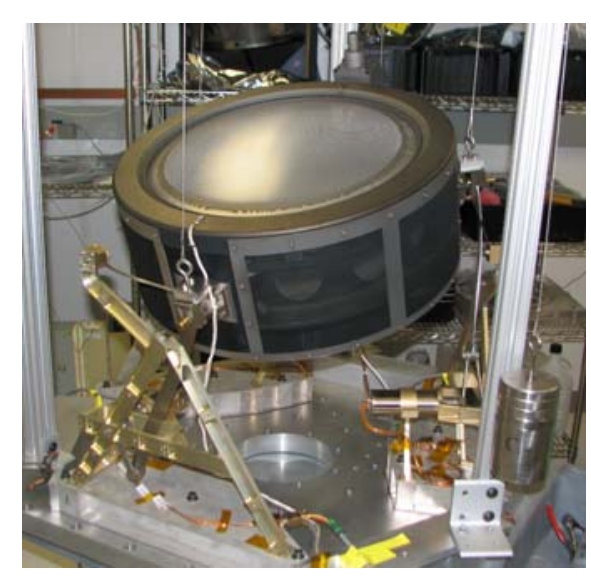

Figure 6.-Gimbal Assembly and PM Thruster undergoing Articulation Testing at JPL.

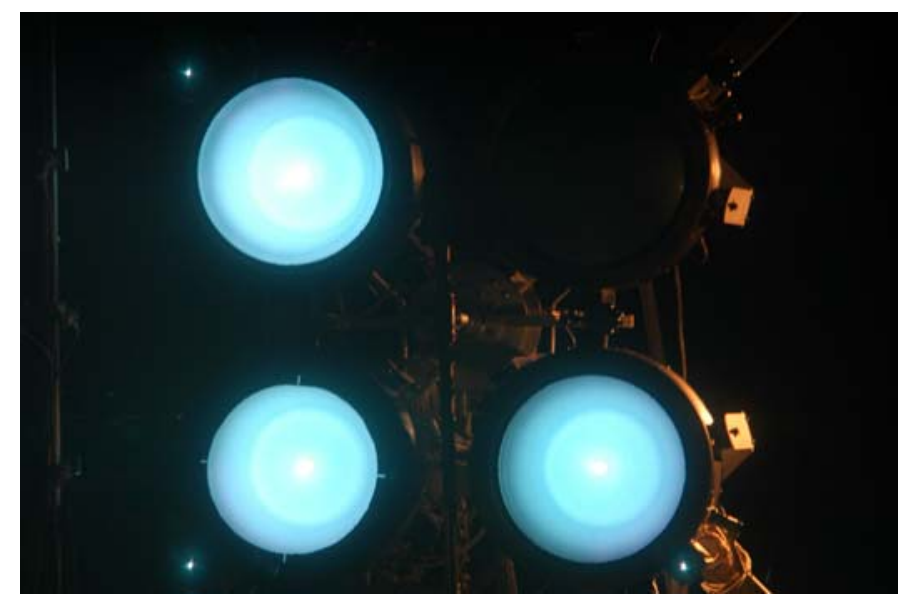

Figure 7.-NEXT EM Thrusters operating at full power in 3+1 Multi-Thruster Array Test bed at NASA GRC.

independent of array configuration. This finding may have significant implications with respect to testing requirements and architectural flexibility for multi-thruster systems.

Single-and 3-thruster string system integration tests are planned during Phase 2, to include operation of the PM thruster with the EM PPU and EM PMS (all under vacuum), with/without the addition of other thrusters into the system, all under command of the DCIU simulator. An exhaustive series of tests are planned, the scope of which is to verify that the integrated system of NEXT components meets the project requirements and verify the interfaces between the system components. Primary objectives of the singlestring $^{7}$ test include: demonstrating operation of thruster over the full NEXT throttle table with the EM PPU and EM PMS; demonstrating operation of the system at off-nominal conditions; and demonstrating recycle and fault protection operation. In total over 100 system level requirements will be validated. Primary objectives of the multi-thruster string test include: validating DCIU and PMS functionality supporting multi-thruster operation; and documenting any potential subsystem interactions.

The multi-thruster system hardware completed in Phase 2 will remain as a flight-system-test bed (representative of expected flight propulsion system) available for continued use as a risk reduction utility to support 1st- user needs.

${ }^{7}$ Single-string refers to a single Thruster-PPU-LPA PMS configuration. 


\section{G. Life Validation}

Validation of the NEXT thruster life requirement is being addressed via a combination of test and analyses. $^{8}$ An EM thruster successfully completed a $2000 \mathrm{hr}$ wear test (ref. 9). A second EM thruster (with PM ion optics manufactured by Aerojet) is presently undergoing long duration life testing at GRC at full power having accumulated approximately $9200 \mathrm{hr}$ of operation to date, processing over $182 \mathrm{~kg}$ of xenon. The thruster has demonstrated over $7.8 \times 10^{6} \mathrm{~N}$-s total impulse; the highest total impulse ever demonstrated by an ion thruster in the history of space propulsion. The EM thruster performance and wear rates of critical thruster components are consistent with model predictions. The life test is scheduled to continue at full power until the $300 \mathrm{~kg}$ requirement is demonstrated at which point the thruster will be power throttled to a mission profile and continue operation. The life capability of the PM thruster will be established by a combination of a) results from the on-going EM thruster life testing, b) similarity analysis to the EM thruster, c) thruster service life modeling, and d) a full-power wear test of a PM thruster.

A service life assessment of the NEXT thruster was conducted at GRC for a number of throttle conditions (ref. 20). The assessment involved the application of several models to evaluate all the known failure modes. For the conditions investigated, the assessment conservatively predicted that the earliest failure would be the accelerator grid, with a structural failure occurring sometime after $730 \mathrm{~kg}$ of xenon throughput. At full power, this would be over $35 \mathrm{khr}$ of operation. Other failure modes were predicted to occur at a condition in excess of $800 \mathrm{~kg}$ thruster xenon throughput; well beyond the mission-derived life time requirement of $300 \mathrm{~kg}$ xenon throughput. Additional analyses of thruster life time over the range of the NEXT full-throttle table were conducted, the results of which are discussed in a following section.

\section{Ion Propulsion System Architecture}

Current best estimates for NEXT flight subsystem characteristics (mass, volume, and power) are listed in table 2.

TABLE 2.-NEXT ION PROPULSION SUBSYTEM CHARACTERISTICS

\begin{tabular}{|c|c|c|c|c|}
\hline Resource & \multicolumn{2}{|c|}{ System } & Current best estimate & Basis \\
\hline \multirow{5}{*}{$\begin{array}{l}\text { Mass } \\
(\mathrm{kg})\end{array}$} & \multicolumn{2}{|c|}{ Thruster } & 12.7 & PM Actual, w/o harness \\
\hline & \multicolumn{2}{|l|}{ PPU } & 34.5 & EM Actual \\
\hline & \multirow[t]{2}{*}{ PMS } & HPA & 1.9 & EM Actual, w/plate and Test Support Equipment \\
\hline & & LPA & 3.1 & EM Actual, w/plate and Test Support Equipment \\
\hline & \multicolumn{2}{|c|}{ Gimbal } & 6 & Breadboard Actual \\
\hline \multirow{5}{*}{$\begin{array}{l}\text { Envelope } \\
(\mathrm{cm})\end{array}$} & \multicolumn{2}{|c|}{ Thruster } & 55 dia by 44 length & PM Actual \\
\hline & \multicolumn{2}{|l|}{ PPU } & 42 by 53 by 14 & EM Actual \\
\hline & \multirow{2}{*}{ PMS } & HPA & 33 by 15 by 6.4 & EM Actual \\
\hline & & LPA & 38 by 30.5 by 6.4 & EM Actual \\
\hline & \multicolumn{2}{|c|}{ Gimbal } & $\begin{array}{c}72 \mathrm{~cm} \text { corner-corner, } \\
61 \mathrm{~cm} \text { flat-flat }\end{array}$ & Breadboard Actual \\
\hline \multirow{5}{*}{$\begin{array}{l}\text { Power } \\
\text { (W) }\end{array}$} & \multicolumn{2}{|c|}{ Thruster $^{9}$} & $540-6860$ & PM Actual \\
\hline & \multicolumn{2}{|l|}{ PPU } & $610-7220$ & Breadboard Actual \\
\hline & \multirow{2}{*}{ PMS } & HPA & 4.3 & EM Actual \\
\hline & & LPA & 15.9 & EM Actual \\
\hline & \multicolumn{2}{|c|}{ Gimbal } & $\mathrm{N} / \mathrm{A}$ & 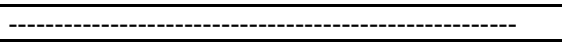 \\
\hline
\end{tabular}

\footnotetext{
${ }^{8}$ The $300 \mathrm{~kg}$ xenon propellant throughput requirement corresponds to about $14.5 \mathrm{khr}$ of operation at full power; $21.7 \mathrm{khr}$ for qualification-level testing.

${ }^{9}$ Input power to the thruster from the PPU.
} 


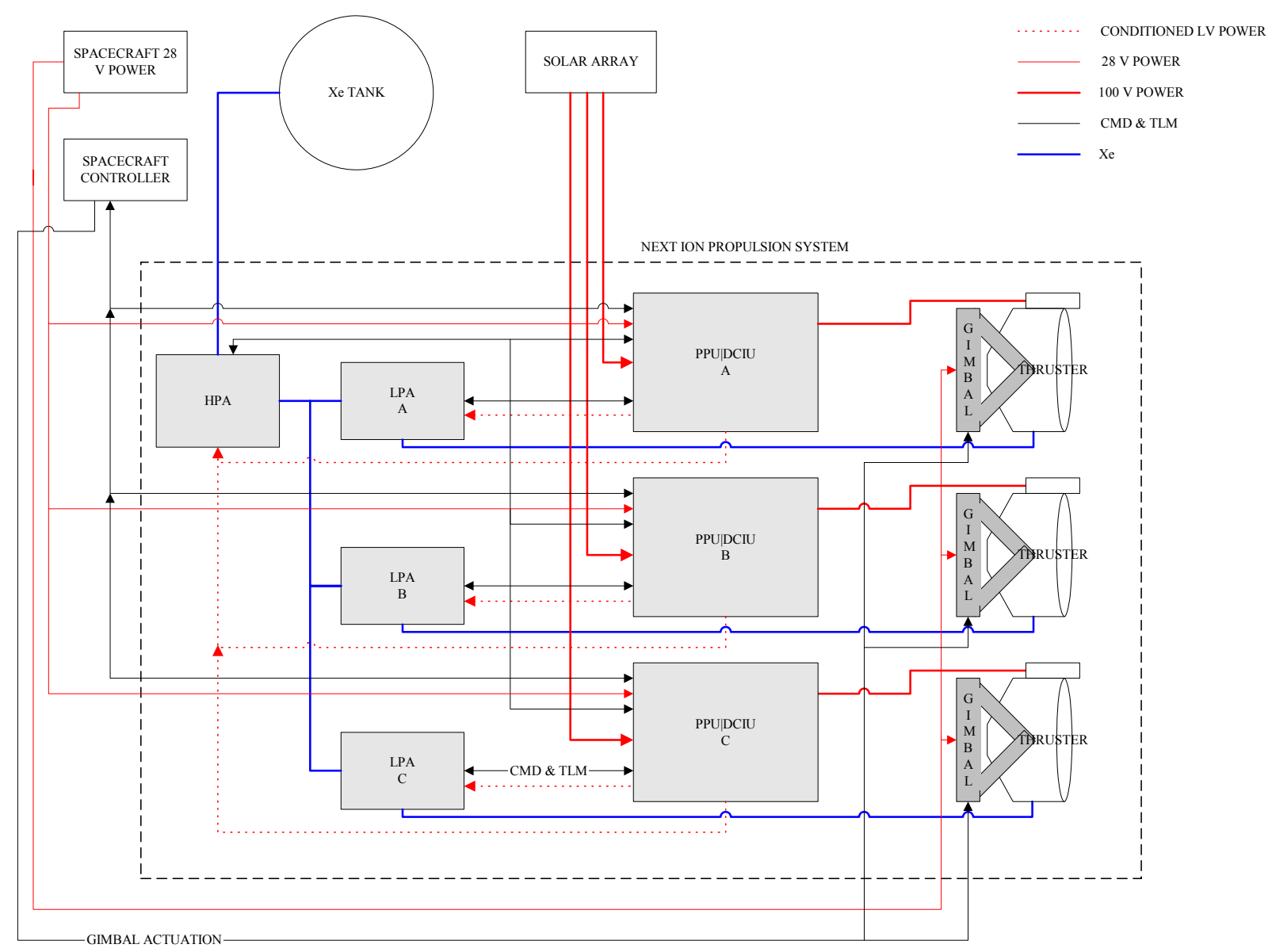

Figure 8.-NEXT IPS 3-String ('2+1') Configuration.

The NEXT IPS is anticipated to consist of a series of independent single-strings (see fig. 1). A thruster string is composed of a thruster and gimbal assembly, a PPU, and a PMS LPA. An HPA and a DCIU $^{10}$ would complete the system. Thruster strings are added for mission performance reasons (to process the available solar power), and an additional string is added for failure tolerance (a spare). A possible NEXT IPS 3-string configuration is illustrated in figure 8. There are a number of system design characteristics that would likely be implemented in a manner different than the Dawn IPS:

$\checkmark$ Although the EM NEXT PPU was designed to operate 2 thrusters, the Dawn IPS issues with relays that switch the power supply outputs between thrusters and the associated software development requirements indicate this to be an unattractive approach with negative system-level reliability consequences. Therefore, the NEXT IPS illustrated in figure 8 assumes no cross-strapping implementation, with direct wiring from each PPU to 1 corresponding thruster.

$\checkmark$ The DS1 and Dawn IPS had separate DCIU boxes, one consequence of which is increased system cost and complexity. Much of the functionality normally associated with a separate DCIU as implemented in DS1 and Dawn has already been propagated into the NEXT EM PPU (thruster sequences). The project intends on building a 2nd-generation PPU which propagates the remaining DCIU functionality (PMS controls) into the PPU box. Figure 8 illustrates this approach, where each PPU and LPA is

\footnotetext{
${ }^{10}$ Alternately, all DCIU functionality could be incorporated into the PPU. This is the intended design approach for a 2 nd generation NEXT PPU.
} 
controlled by a separate digital interface contained within the PPU box. Each of these dedicated DCIUs is capable of commanding the single HPA.

$\checkmark$ The gimbal drive electronics are assumed to be maintained as a spacecraft function and are not processed through the DCIU as implemented on Dawn.

Spacecraft integration should be simplified with the NEXT IPS, as compared to NSTAR-based IPS, due to improved capabilities and features:

Less thruster strings per mission total impulse are required due to the higher total impulse capability of the NEXT thruster;

$\checkmark$ Modular, simplified xenon feed system;

$\checkmark$ The NEXT PPU is compatible with wider baseplate thermal range than NSTAR; and

$\checkmark$ The gimbal has smaller footprint than the NSTAR thruster Dawn gimbal.

\section{Performance}

\section{A. System}

NEXT provides significant performance benefits as compared to NSTAR SOA. The higher propellant throughput capability of the thruster and its greater total impulse allow it to accomplish low power, high $\Delta \mathrm{V}$ missions (Dawn-like) with fewer numbers of thrusters. The higher power and thrust capability of NEXT allow power-driven missions (outer-planet) to be accomplished with fewer thruster strings. The higher specific impulse capability of the NEXT thruster reduces the spacecraft propellant mass, thus accommodating more payload mass. The increased system power throttling range (11.9-to-1 PPU input power range for NEXT versus 4.8-to-1 for NSTAR) allows single thruster string operation over a much broader range of solar distances.

Table 3, the NEXT throttle table, documents the performance data for the thruster (representative of both EM and PM thrusters) and data obtained from the breadboard PPU. System efficiencies, defined here as the product of the thruster and PPU efficiencies, are also listed in the throttle table. As noted from the NEXT throttle table, the PPU input power ranges from $7.22 \mathrm{~kW}$ down to $0.61 \mathrm{~kW}$, corresponding to a specific impulse range of about 4190 to $1400 \mathrm{~s}$, and thrust range from about $236 \mathrm{mN}$ down to about $26 \mathrm{mN}$. Over this input power range the thruster, PPU, and system efficiencies vary from about 0.71 to $0.33,0.95$ to 0.89 , and 0.67 to 0.29 respectively. Figures 9,10 , and 11 show plots of: the thruster and system efficiencies vs. specific impulse; the thrust as a function of PPU input power; and the specific impulse as a function of PPU input power.

Analyses of thruster life time were conducted by the author over the entirety of the performance conditions of the NEXT throttle table, and these results are also listed in table 3. The calculation methodology is described in reference 19, and includes ion optics electrode wear, as well as cathode emitter and cathode keeper wear. Thruster life, $L_{t}$, in khr, and total Xe propellant throughput capability, $\mathrm{M}_{\text {T-TOT}}$, in $\mathrm{kg}$, are listed, as well as the corresponding total impulse capability of the thruster, $I$, in N-s.

Consistent with prior calculations, the total propellant throughput capability is projected to be in excess of $>700 \mathrm{~kg}$ at full power and over most of the throttle table. However, for the 3 lowest-power conditions in the throttle table,${ }^{11}$ the throughput capability is projected to be less than the qualification requirement of $450 \mathrm{~kg}$. This is due to operation at high magnitudes of accelerator electrode voltage to yield high beam current. However, even at these conditions, the projected life time is in excess of $35 \mathrm{khr}$.

\footnotetext{
${ }^{11}$ These 3 throttle conditions were added to the NEXT throttle table after Phase 1 to accommodate investigating NEXT IPS applications to Discovery- and New Frontiers-class missions.
} 
TABLE 3.-NEXT THROTTLE TABLE: DEMONSTRATED THRUSTER AND PPU PERFORMANCE (BOL)

\begin{tabular}{|c|c|c|c|c|c|c|c|c|c|}
\hline $\begin{array}{c}V_{b p s}, \\
\mathrm{~V}\end{array}$ & $\begin{array}{c}F, \\
\mathrm{mN}\end{array}$ & $\begin{array}{c}I_{s p}, \\
\mathrm{~s}\end{array}$ & $\eta_{t}$ & $\begin{array}{c}P_{i n-P P U}, \\
\mathrm{~kW}\end{array}$ & $\eta_{P P U}$ & $\eta_{\text {System }}$ & $\begin{array}{c}L_{t} \\
\mathrm{khr}\end{array}$ & $\begin{array}{c}M_{\text {T-TOT, }} \\
\mathrm{kg} \mathrm{Xe}\end{array}$ & $I, \times 10^{7} \mathrm{~N}-\mathrm{s}$ \\
\hline \multicolumn{10}{|c|}{$M_{T}=5.76 \mathrm{mg} / \mathrm{s} ; I_{b}=3.52 \mathrm{~A}$} \\
\hline 1800 & 236 & 4190 & 0.71 & 7.220 & 0.95 & 0.67 & 37.6 & 780 & 3.20 \\
\hline 1567 & 221 & 3910 & 0.70 & 6.385 & 0.95 & 0.66 & 37.6 & 780 & 2.99 \\
\hline 1396 & 208 & 3690 & 0.69 & 5.780 & 0.95 & 0.65 & 37.6 & 780 & 2.82 \\
\hline 1179 & 192 & 3395 & 0.68 & 4.965 & 0.95 & 0.64 & 40.5 & 840 & 2.80 \\
\hline \multicolumn{10}{|c|}{$M_{T}=5.12 \mathrm{mg} / \mathrm{s} ; I_{b}=3.10 \mathrm{~A}$} \\
\hline 1800 & 208 & 4150 & 0.70 & 6.390 & 0.95 & 0.66 & 43.0 & 795 & 3.22 \\
\hline 1567 & 194 & 3875 & 0.69 & 5.660 & 0.95 & 0.65 & 43.0 & 795 & 3.01 \\
\hline 1396 & 184 & 3660 & 0.68 & 5.085 & 0.95 & 0.65 & 43.0 & 795 & 2.84 \\
\hline 1179 & 169 & 3360 & 0.67 & 4.490 & 0.95 & 0.63 & 46.3 & 855 & 2.81 \\
\hline \multicolumn{10}{|c|}{$M_{T}=4.46 \mathrm{mg} / \mathrm{s} ; I_{b}=2.70 \mathrm{~A}$} \\
\hline 1800 & 181 & 4150 & 0.70 & 5.600 & 0.95 & 0.66 & 49.1 & 790 & 3.20 \\
\hline 1567 & 169 & 3875 & 0.69 & 4.920 & 0.95 & 0.65 & 49.1 & 790 & 2.99 \\
\hline 1396 & 160 & 3660 & 0.68 & 4.455 & 0.95 & 0.64 & 49.1 & 790 & 2.83 \\
\hline 1179 & 147 & 3360 & 0.67 & 3.860 & 0.94 & 0.63 & 52.9 & 850 & 2.80 \\
\hline 1021 & 137 & 3125 & 0.65 & 3.425 & 0.94 & 0.61 & 65.7 & 1055 & 3.23 \\
\hline \multicolumn{10}{|c|}{$M_{T}=3.92 \mathrm{mg} / \mathrm{s} ; I_{b}=2.35 \mathrm{~A}$} \\
\hline 1800 & 158 & 4100 & 0.69 & 4.870 & 0.95 & 0.65 & 56.5 & 795 & 3.21 \\
\hline 1567 & 147 & 3830 & 0.68 & 4.315 & 0.95 & 0.64 & 56.5 & 795 & 2.99 \\
\hline 1396 & 139 & 3615 & 0.67 & 3.910 & 0.94 & 0.63 & 56.5 & 795 & 2.83 \\
\hline 1179 & 128 & 3325 & 0.66 & 3.390 & 0.94 & 0.62 & 60.8 & 860 & 2.80 \\
\hline 1021 & 119 & 3090 & 0.64 & 3.010 & 0.94 & 0.60 & 75.5 & 1065 & 3.23 \\
\hline \multicolumn{10}{|c|}{$M_{T}=3.16 \mathrm{mg} / \mathrm{s} ; I_{b}=2.00 \mathrm{~A}$} \\
\hline 1800 & 134 & 4310 & 0.71 & 4.235 & 0.95 & 0.67 & 66.4 & 755 & 3.20 \\
\hline 1567 & 125 & 4025 & 0.70 & 3.760 & 0.94 & 0.66 & 66.4 & 755 & 2.98 \\
\hline 1396 & 118 & 3800 & 0.69 & 3.415 & 0.94 & 0.64 & 66.4 & 755 & 2.82 \\
\hline 1179 & 108 & 3490 & 0.67 & 2.970 & 0.94 & 0.62 & 71.5 & 815 & 2.79 \\
\hline 1021 & 101 & 3250 & 0.65 & 2.620 & 0.94 & 0.61 & 88.9 & 1010 & 3.22 \\
\hline \multicolumn{10}{|c|}{$M_{T}=2.60 \mathrm{mg} / \mathrm{s} ; I_{b}=1.60 \mathrm{~A}$} \\
\hline 1800 & 107 & 4190 & 0.68 & 3.460 & 0.94 & 0.64 & 83.6 & 785 & 3.22 \\
\hline 1567 & 99.9 & 3910 & 0.67 & 3.080 & 0.94 & 0.62 & 83.6 & 785 & 3.01 \\
\hline 1396 & 94.3 & 3690 & 0.65 & 2.765 & 0.94 & 0.61 & 83.6 & 785 & 2.84 \\
\hline 1179 & 86.7 & 3395 & 0.64 & 2.415 & 0.94 & 0.60 & 90.1 & 845 & 2.81 \\
\hline 1021 & 80.6 & 3155 & 0.62 & 2.160 & 0.94 & 0.58 & 112 & 1050 & 3.25 \\
\hline \multicolumn{10}{|c|}{$M_{T}=2.05 \mathrm{mg} / \mathrm{s} ; I_{b}=1.20 \mathrm{~A}$} \\
\hline 1800 & 80.2 & 4000 & 0.65 & 2.585 & 0.94 & 0.61 & 110 & 815 & 3.18 \\
\hline 1567 & 74.9 & 3735 & 0.63 & 2.300 & 0.94 & 0.60 & 110 & 815 & 2.97 \\
\hline 1396 & 70.7 & 3525 & 0.62 & 2.090 & 0.94 & 0.59 & 110 & 815 & 2.80 \\
\hline 1179 & 65.0 & 3240 & 0.61 & 1.825 & 0.93 & 0.57 & 119 & 875 & 2.78 \\
\hline 1021 & 60.4 & 3015 & 0.59 & 1.635 & 0.93 & 0.55 & 147 & 1090 & 3.21 \\
\hline 936 & 57.8 & 2885 & 0.58 & 1.520 & 0.94 & 0.54 & 196 & 1445 & 4.07 \\
\hline 850 & 55.1 & 2745 & 0.56 & 1.415 & 0.94 & 0.53 & 293 & 2160 & 5.80 \\
\hline 679 & 49.2 & 2450 & 0.53 & 1.210 & 0.93 & 0.49 & 366 & 2705 & 6.49 \\
\hline 650 & 48.1 & 2400 & 0.52 & 1.175 & 0.93 & 0.48 & 212 & 1565 & 3.68 \\
\hline 400 & 37.2 & 1855 & 0.43 & 0.865 & 0.91 & 0.39 & 49.3 & 365 & 0.66 \\
\hline 300 & 31.8 & 1585 & 0.37 & 0.740 & 0.90 & 0.33 & 36.5 & 270 & 0.42 \\
\hline \multicolumn{10}{|c|}{$M_{T}=1.85 \mathrm{mg} / \mathrm{s} ; I_{b}=1.00 \mathrm{~A}$} \\
\hline 275 & 25.5 & 1400 & 0.33 & 0.610 & 0.89 & 0.29 & 46.3 & 310 & 0.42 \\
\hline
\end{tabular}




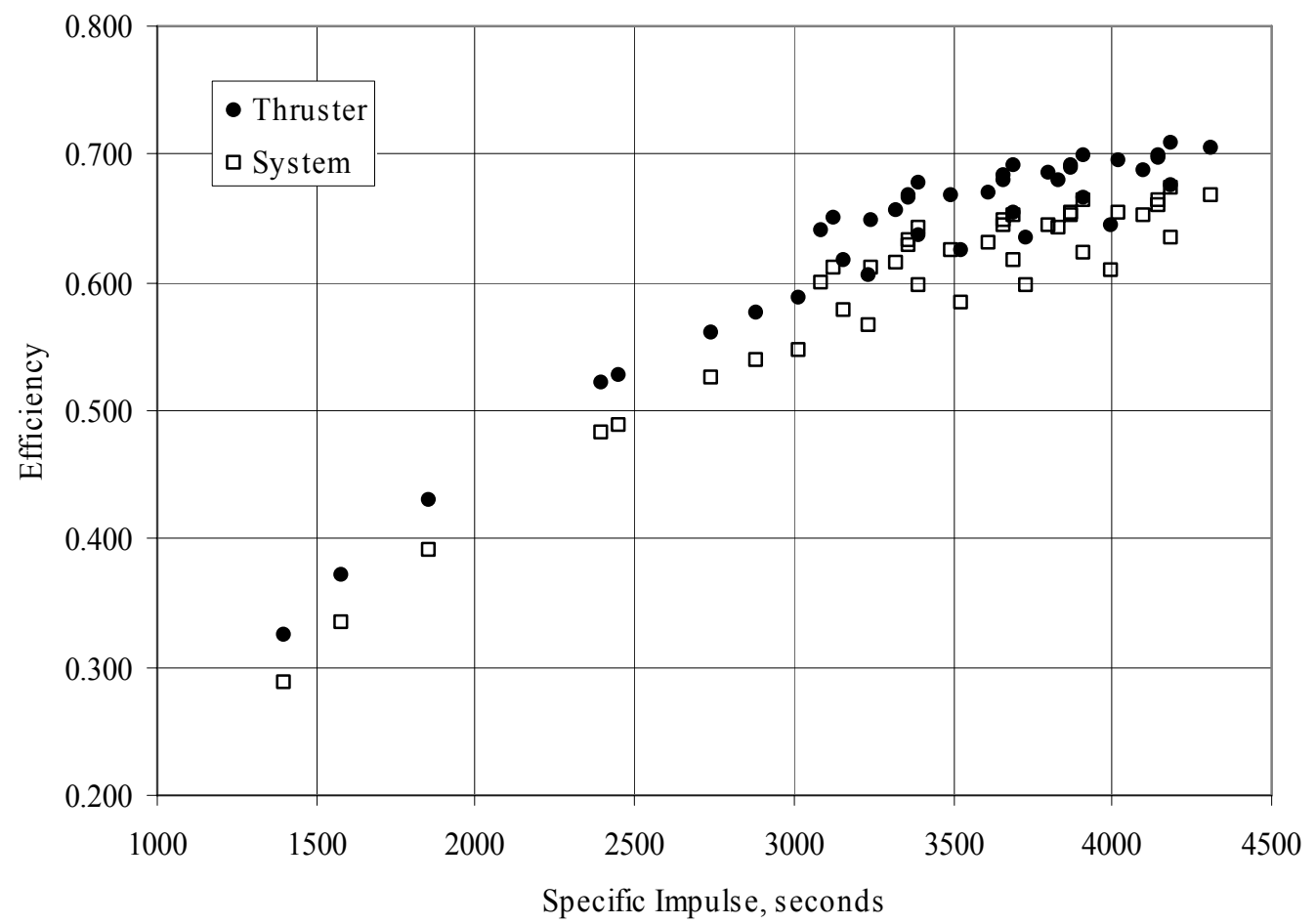

Figure 9._NEXT Thruster and System Efficiency versus Specific Impulse.

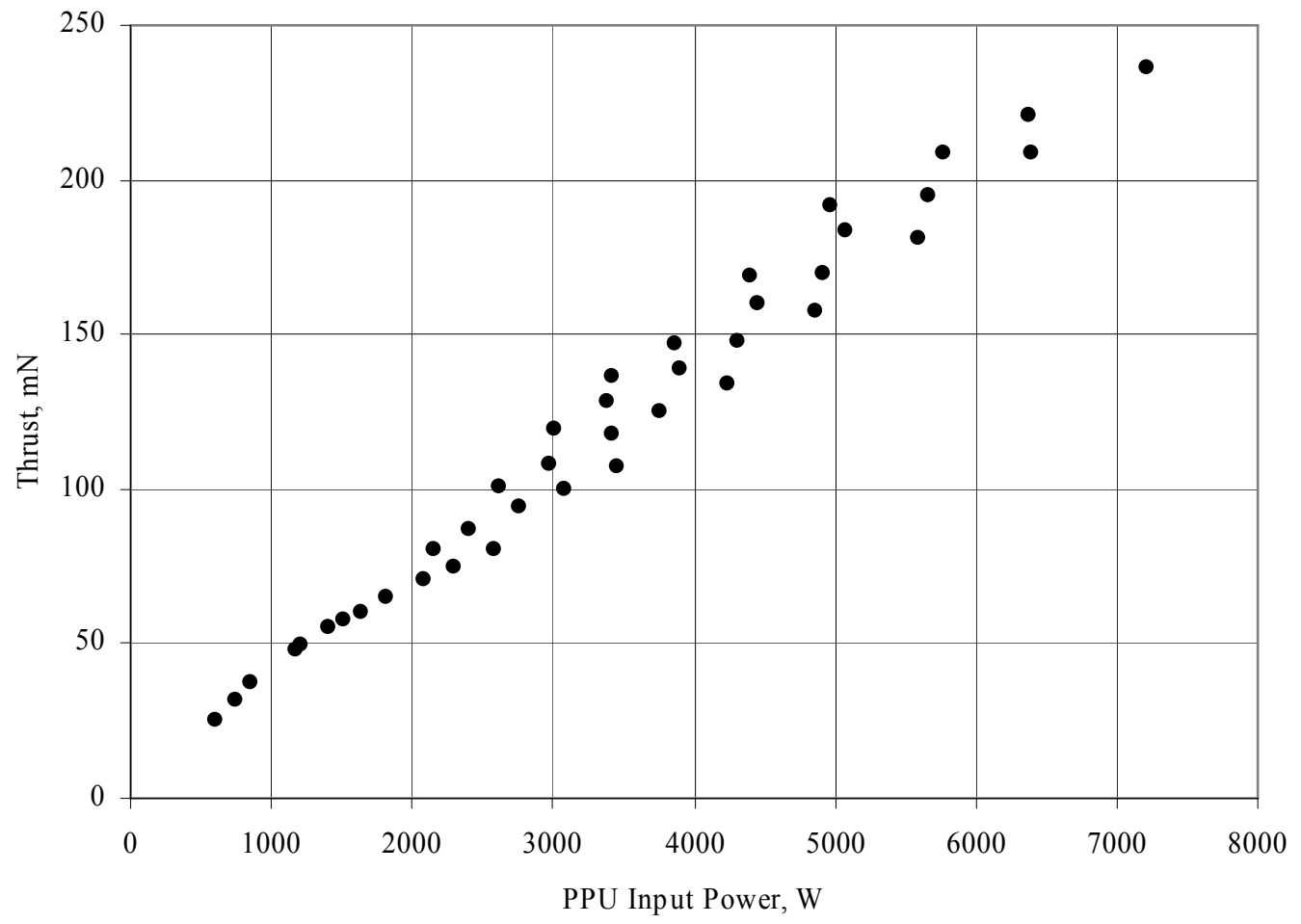

Figure 10.-NEXT Thrust as a function of PPU Input Power. 


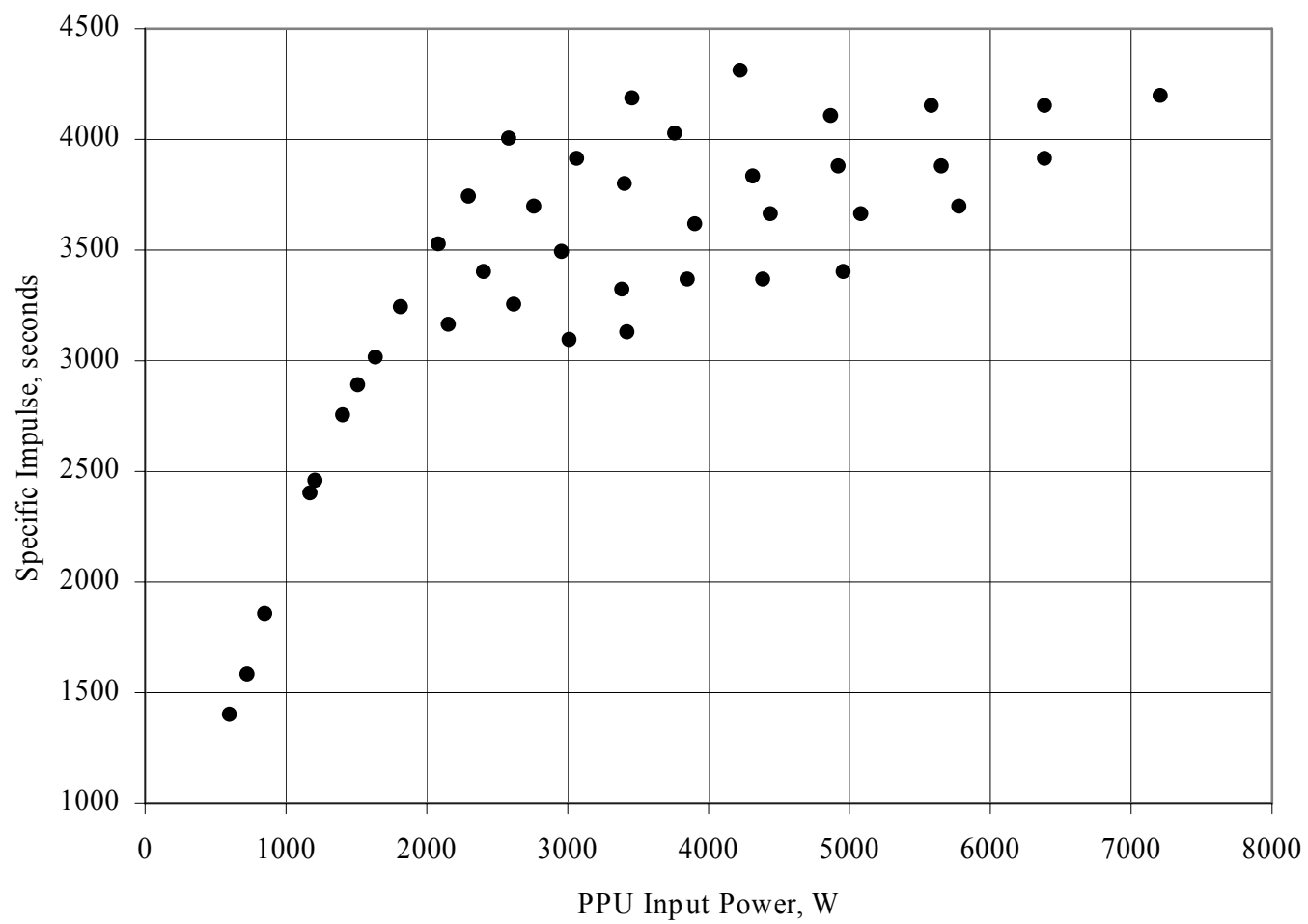

Figure 11.-NEXT Specific Impulse as a function of PPU Input Power.

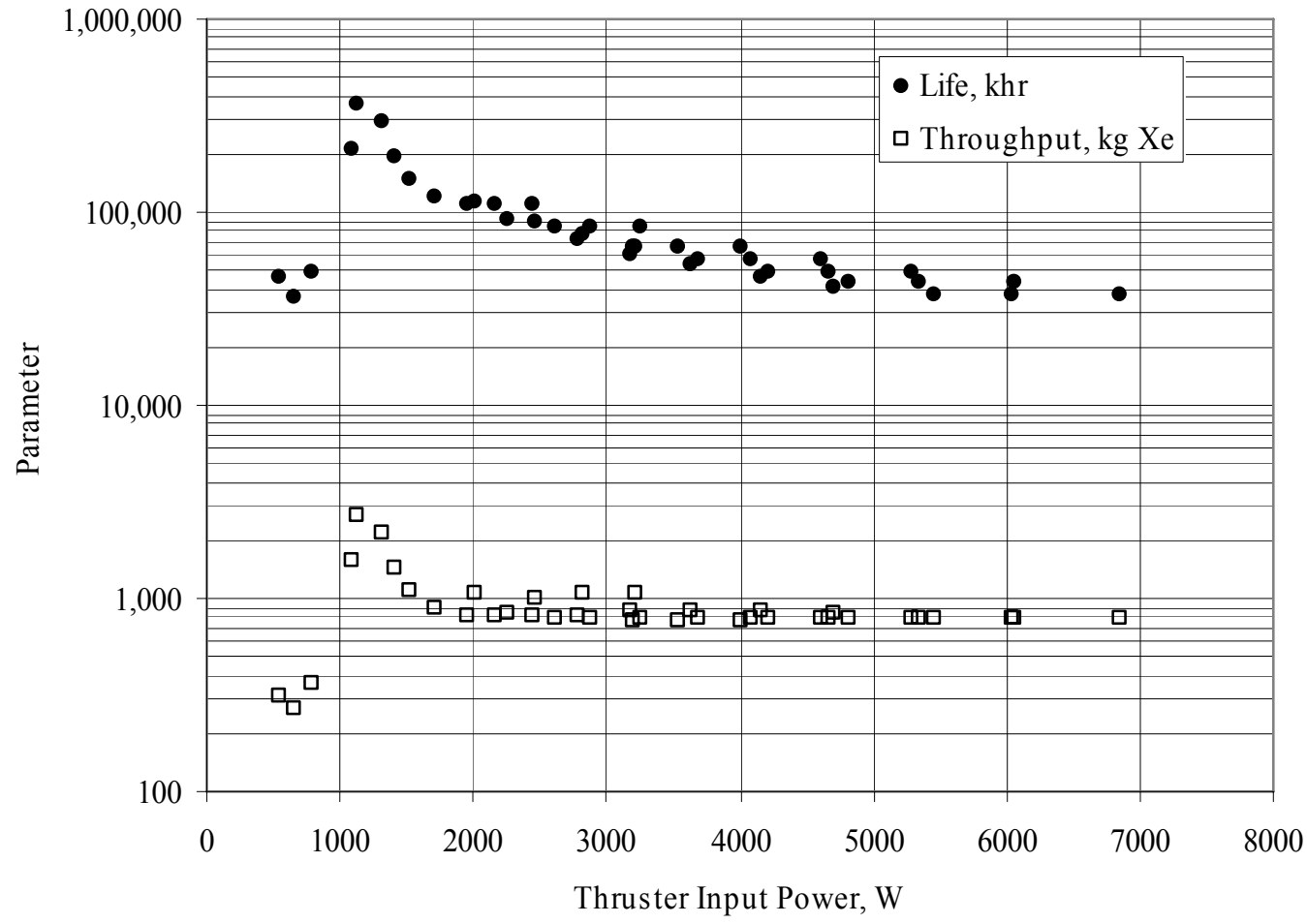

Figure 12.-Projected NEXT Thruster Life and Propellant Throughput versus NEXT Thruster Input Power, from NEXT Throttle Table. 


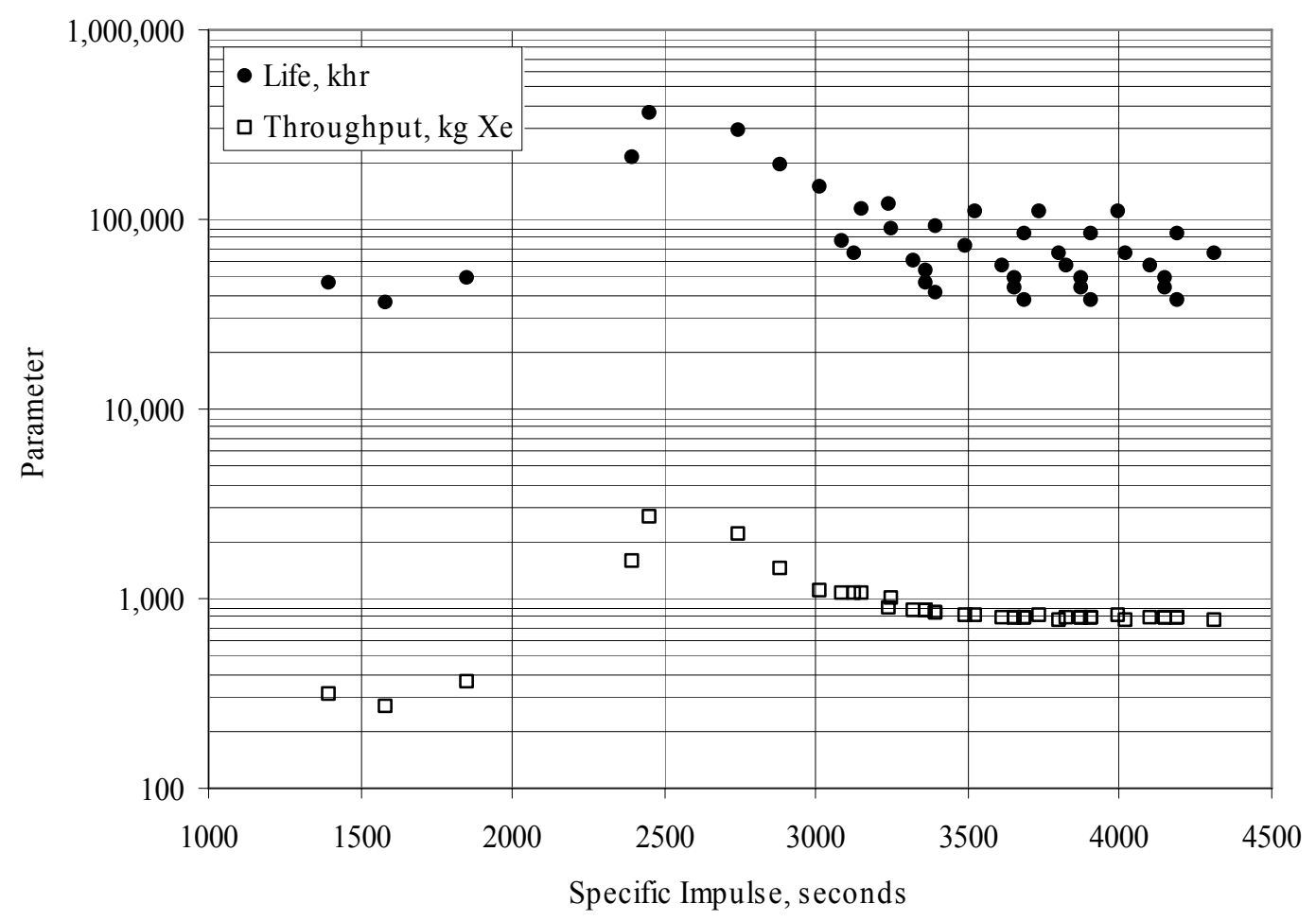

Figure 13.-_Projected NEXT Thruster Life and Propellant Throughput versus NEXT Thruster Specific Impulse, from NEXT Throttle Table.

As such the reduced propellant throughput at these throttle points is of no consequence from a mission application stand point. Figures 12 and 13 plot the thruster life time and propellant throughput capability as a function of thruster input power and specific impulse respectively. As noted in from figure 12, the projected life time and propellant throughput of the thruster is $>35 \mathrm{khr}$ and $>>700 \mathrm{~kg}$ for most of the input power level, but experiences an inflection at $<1.1 \mathrm{~kW}$. From figure 13, this inflection point of reduced life time and throughput corresponds to specific impulse values less than about $2500 \mathrm{~s}$. Summarizing the analyses performed to estimate NEXT thruster life capability versus throttle table throttle condition:

$\checkmark$ The minimum life time is established by the ion optics accelerator electrode for all throttle conditions;

$\checkmark$ The minimum life time is at full power, with the exception of operating points at thruster input powers $\leq 665 \mathrm{~W}$;

$\checkmark$ For most of the throttle table the projected throughput capability is relatively constant at about $800 \mathrm{~kg}$, corresponding to a total impulse of about $3 \times 10^{7} \mathrm{~N}-\mathrm{s}$;

$\checkmark$ The minimum throughput capability of the thruster is at low power;

$\checkmark$ The cathode emitter wear mechanisms (tungstate formation and barium reactions, and barium depletion) and keeper erosion due to ion bombardment are not anticipated to be thruster life limiters.

Table 4 lists demonstrated NEXT thruster performance over an extended-performance throttle table. These conditions - high power up to $14 \mathrm{~kW}$, and high thrust-to-power - were investigated to understand the performance limits of the thruster (ref. 21); the NEXT thruster without modification is capable of operating over the conditions identified. Corresponding life times are projected in table 4 and these range from about 7.5 to $25 \mathrm{khr}$, with propellant throughputs from about $245 \mathrm{~kg}$ to $>800 \mathrm{~kg}$. The total impulse and throughput capability of the thruster over most of the high-power portion of the throttle table are consistent with those values estimated for the nominal NEXT throttle table (table 3). Since the NEXT PPU is capable of operating at twice its maximum output beam current $(7 \mathrm{~A})$ at about half of its maximum output beam voltage $(\sim 1000 \mathrm{~V})$, the NEXT PPU as-is can operate the thruster over all the high 
thrust-to-power conditions identified in the extended-performance throttle table. It is also capable of operating at high power conditions with beam currents of $5.80 \mathrm{~A}$ and beam voltages $\leq 1179 \mathrm{~V}$, and the 7.0 A beam current condition at $1021 \mathrm{~V}$ beam voltage. Additional beam modules would need to be added to the PPU to capture the remaining extended-performance operating conditions. The PMS with appropriate re-sizing of the FCDs could operate over the entirety of the extended-performance throttle table.

TABLE 4.-EXTENDED-PERFORMANCE THROTTLE TABLE: DEMONSTRATED THRUSTER PERFORMANCE (BOL)

\begin{tabular}{|c|c|c|c|c|c|c|c|c|c|}
\hline $\begin{array}{c}V_{b p s}, \\
\mathrm{~V}\end{array}$ & $\begin{array}{l}F, \\
\mathrm{mN}\end{array}$ & $\begin{array}{c}I_{s p}, \\
\mathrm{~S} \\
\end{array}$ & $\eta_{t}$ & $P_{\text {in-t }}, \mathrm{kW}$ & $M_{T}, \mathrm{mg} / \mathrm{s}$ & $\begin{array}{c}I_{b}, \\
\mathrm{~A}\end{array}$ & $\begin{array}{c}L_{t}, \\
\mathrm{khr}\end{array}$ & $\begin{array}{c}M_{T-T O T}, \\
\mathrm{~kg} \mathrm{Xe}\end{array}$ & $\begin{array}{c}I, \times 10^{7} \mathrm{~N}- \\
\mathrm{S}\end{array}$ \\
\hline \multicolumn{10}{|c|}{ High Power Operation } \\
\hline 1800 & 389 & 4420 & 0.75 & 11.250 & 8.96 & 5.80 & 25.3 & 815 & 3.53 \\
\hline 1567 & 363 & 4130 & 0.74 & 9.930 & 8.96 & 5.80 & 25.3 & 815 & 3.30 \\
\hline 1396 & 343 & 3900 & 0.73 & 8.960 & 8.96 & 5.80 & 25.3 & 815 & 3.11 \\
\hline 1179 & 315 & 3585 & 0.72 & 7.730 & 8.96 & 5.80 & 25.3 & 815 & 2.86 \\
\hline 1021 & 293 & 3335 & 0.70 & 6.830 & 8.96 & 5.80 & 24.3 & 785 & 2.56 \\
\hline 1800 & 472 & 4460 & 0.76 & 13.645 & 10.79 & 7.04 & 18.7 & 730 & 3.18 \\
\hline 1567 & 441 & 4165 & 0.75 & 12.040 & 10.79 & 7.04 & 18.7 & 730 & 2.97 \\
\hline 1396 & 416 & 3930 & 0.74 & 10.865 & 10.79 & 7.04 & 18.7 & 730 & 2.80 \\
\hline 1179 & 382 & 3615 & 0.72 & 9.370 & 10.79 & 7.04 & 18.7 & 730 & 2.58 \\
\hline 1021 & 356 & 3360 & 0.71 & 8.285 & 10.79 & 7.04 & 9.66 & 375 & 1.24 \\
\hline \multicolumn{10}{|c|}{ High Thrust-to-Power Operation } \\
\hline 700 & 147 & 2655 & 0.62 & 3.120 & 5.64 & 3.52 & 33.7 & 685 & 1.78 \\
\hline 700 & 167 & 2675 & 0.62 & 3.515 & 6.35 & 4.00 & 20.8 & 475 & 1.25 \\
\hline 700 & 187 & 2670 & 0.62 & 3.920 & 7.15 & 4.50 & 14.4 & 370 & 0.97 \\
\hline 700 & 208 & 2700 & 0.64 & 4.325 & 7.84 & 5.00 & 10.8 & 305 & 0.81 \\
\hline 700 & 228 & 2710 & 0.64 & 4.720 & 8.59 & 5.50 & 8.50 & 265 & 0.70 \\
\hline 700 & 240 & 2715 & 0.65 & 4.940 & 9.04 & 5.80 & 7.50 & 245 & 0.65 \\
\hline
\end{tabular}

\section{B. Mission}

The NEXT project began with Flagship-class Deep Space Design Reference Missions (a Titan Explorer, and Neptune Orbiter, both assuming aerocapture at the destinations) as the "design driver" mission applications. A refocus study was conducted in 2004 to investigate NEXT IPS applications to both Discovery- and New Frontiers-class missions. Several Discovery-class mission studies shows that NEXT outperforms SOA NSTAR, yielding higher net payload mass with fewer thrusters. NEXT also was either mission-enhancing (relative to chemical propulsion) or mission-enabling for several New Frontiersand Flagship-class studies. A summary of these findings are listed in table 5 which indicates that NEXT provides mission benefits across all planetary science mission classes. First-user costs however are identified as an area of concern.

TABLE 5.-SUMMARY OF NEXT IPS MISSION BENEFITS

\begin{tabular}{|c|c|}
\hline Mission & NEXT Mission Benefits \\
\hline $\begin{array}{ll}\text { Discovery- Small Body Missions: } \\
\checkmark & \text { Near Earth Asteroid Rendezvous } \\
\checkmark & \text { Vesta-Ceres Rendezvous (Dawn) } \\
\checkmark & \text { Comet Rendezvous } \\
\checkmark & \text { Deimos Sample Return } \\
\end{array}$ & $\begin{array}{l}\text { Higher net payload mass with fewer thrusters than NSTAR } \\
\text { system }\end{array}$ \\
\hline $\begin{array}{l}\text { New Frontiers: } \\
\checkmark \quad \text { Comet Surface Sample Return }\end{array}$ & $\begin{array}{l}\text { Higher net payload mass than NSTAR, with, simpler EP } \\
\text { System: } 2+1 \text { NEXT versus } 4+1 \text { NSTAR thrusters }\end{array}$ \\
\hline $\begin{array}{l}\text { New Frontiers: } \\
\checkmark \quad \text { Titan Direct Lander }\end{array}$ & $\begin{array}{l}>700 \mathrm{~kg} \text { entry package with } 1+1 \text { NEXT system, potentially } \\
\text { within New Frontiers cost cap }\end{array}$ \\
\hline $\begin{array}{l}\text { Flagship-Saturn System Missions: } \\
\checkmark \quad \text { Titan } \\
\checkmark \quad \text { Enceladus }\end{array}$ & $\begin{array}{l}>2400 \mathrm{~kg} \text { to Saturn Orbit Insertion with 1+1 NEXT system, } \\
\text { EGA and Atlas } 5 \text { EELV - doubles delivered mass of } \\
\text { chemical/JGA approach } \\
>4000 \mathrm{~kg} \text { to Saturn Orbit Insertion with } 3+1 \text { NEXT system, } \\
\text { EGA and Delta IV Heavy }\end{array}$ \\
\hline
\end{tabular}




\section{Transition to Flight}

A number of project activities are being conducted to increase the likelihood of transitioning the NEXT IPS technology to flight in the near-term, and do so with minimal technical difficulties and at low cost. These activities include: reviewing Dawn IPS 'lessons-learned' and implementing strategies to mitigate the likelihood of experiencing similar difficulties; conducting independent reviews of NEXT technology status with representation from the user community and incorporating the feedback into the development plan; and identifying additional technology development and validation activities which may be of value in transitioning the TRL 6 IPS technology to flight and reduce barriers to 1st-user implementation (reduce non-recurring costs, etc.). These aspects are discussed further.

The NEXT project has placed particular emphasis on key aspects of IPS development with the intention of avoiding the difficulties experienced by the Dawn mission in transitioning the NSTAR-based technology to an operational ion propulsion system (ref. 7). Some of the issues experienced during Dawn IPS development, and mitigation strategies implemented under NEXT IPS development are listed in table 6.

TABLE 6.-DAWN ISSUES AND NEXT MITIGATIONS

\begin{tabular}{|c|c|c|}
\hline Element & Dawn IPS Issue & NEXT IPS Mitigation Strategy \\
\hline \multirow[t]{3}{*}{ Thruster } & $\begin{array}{l}\text { Inadequate documentation to reproduce } \\
\text { NSTAR/DS1 thrusters }\end{array}$ & $\begin{array}{l}\checkmark \\
\checkmark \text { Proto-flight thruster build phase executed } \\
\text { Proto-flight thruster drawings and work instructions to } \\
\text { be released under contractors flight hardware } \\
\text { configuration management system at completion of } \\
\text { Phase } 2\end{array}$ \\
\hline & $\begin{array}{l}\text { Difficulty in assembling and alignment of ion } \\
\text { optics }\end{array}$ & $\begin{array}{l}\text { Improved manufacturing processes and mounting design } \\
\text { reduce alignment touch labor and improve alignment } \\
\text { precision }\end{array}$ \\
\hline & $\begin{array}{l}\text { Design changes identified by on-going } \\
\text { thruster life test needed to be implemented } \\
\text { into the flight thruster design and build } \\
\text { process }\end{array}$ & $\begin{array}{l}\checkmark \text { Design changes identified by (early) execution of } \\
\text { wear- and long-duration tests of NEXT thrusters have } \\
\text { already been incorporated into the PM design } \\
\checkmark \quad \text { Mission-derived requirement of } 300 \mathrm{~kg} \text { propellant } \\
\text { throughput will be demonstrated by 1st-quarter 2008; } \\
\text { well in advance of commitment to flight }\end{array}$ \\
\hline \multirow[t]{3}{*}{ PPU } & $\begin{array}{l}\text { Inadequate documentation to reproduce } \\
\text { NSTAR/DS1 PPUs }\end{array}$ & $\begin{array}{l}\text { PPU manufactured by contractor's flight production group } \\
\text { with all documentation - manufacturing drawings and } \\
\text { assembly instructions - completed and under } \\
\text { configuration control prior to EM PPU build }\end{array}$ \\
\hline & $\begin{array}{l}\text { The DS1 PPU was not designed to be } \\
\text { manufacturable resulting in fabrication, } \\
\text { assembly and test issues }\end{array}$ & $\begin{array}{l}\text { The NEXT PPU has a modular construction } \\
\text { which is: designed for semi-automatic testing at module } \\
\text { level; designed for manufacturability; relatively low cost; } \\
\text { and contains parts which have short lead time, are new, } \\
\text { and available }\end{array}$ \\
\hline & $\begin{array}{l}\text { No thermal cycle testing or analysis } \\
\text { of the NSTAR/DS1 PPU was completed } \\
\text { prior to Dawn }\end{array}$ & $\begin{array}{l}\text { Thermal cycle testing and analysis of the NEXT PPU } \\
\text { will be completed during Phase } 2\end{array}$ \\
\hline PMS & $\begin{array}{l}\text { Dawn PMS (a 3-thruster version of the DS1 } \\
\text { system) is complex, bulky, and required } \\
\text { extensive modification to satisfy mission } \\
\text { requirements }\end{array}$ & $\begin{array}{ll}\checkmark & \text { DS1 and Dawn feed system engineers heavily } \\
\text { involved in NEXT design from project initiation } \\
\checkmark & \text { NEXT PMS design is lightweight and compact }\end{array}$ \\
\hline
\end{tabular}

An independent review (IR) of the NEXT project was conducted with the objective of providing an assessment of the NEXT project and its ability to meet the project objectives. Specifically the IR board, which included participation from the potential user community, was asked to review the planned validation and qualification tests and analyses for the baseline project, and identify project risks and provide recommendations for project modifications. With implementation of 11 findings, the IR board concluded that the NEXT project is on a path that would effectively support future users. The NEXT team reviewed and concurred with all of the IR findings and is in the process of implementing the board findings within the constraints of the development program.

As a product of the Dawn lessons learned, the IR findings, and EP architecture studies conducted under ISPT, the NEXT project has identified additional technology development and validation activities 
which may facilitate the transition of the NEXT IPS to flight and reduce barriers to 1st-user implementation. These tasks (see table 7) include manufacturing of a second PM thruster under configuration control which could be available as a qualification unit to the 1st-user, fabrication of an updated (2nd-generation) NEXT PPU with integral DCIU, and use of the NASA Multi-Thruster Array as a flight-representative propulsion system test bed. It is anticipated that by taking these additional transition steps the 1st-user IPS implementation costs will be reduced. ${ }^{12}$

\begin{tabular}{|c|c|}
\hline System element & Activity \\
\hline Thruster & $\begin{array}{ll}\checkmark & \text { Complete } 2^{\text {nd }} \text { PM thruster under configuration control } \\
\checkmark & \text { Update thruster design and analysis as required }\end{array}$ \\
\hline PPU/DCIU & $\begin{array}{ll}\checkmark & \text { Manufacture } 2^{\text {nd }} \text {-generation PPU incorporating all DCIU functionality } \\
\text { internal to PPU } \\
\checkmark & \text { Complete qualification-level testing of } 2^{\text {nd }} \text {-generation PPU } \\
\checkmark & \text { Update PPU analysis as required, including reliability } \\
\end{array}$ \\
\hline System & $\begin{array}{l}\text { Maintain NEXT Multi-Thruster Array-with integrated EM and PM thrusters, } \\
\text { EM PPU, EM PMS, and gimbal—as a multi-engine flight-system-test bed to } \\
\text { support flight system integration activities }\end{array}$ \\
\hline
\end{tabular}

\section{Summary}

NEXT project activities have brought next-generation ion propulsion technology to a mature state, with existing tasks completing the majority of the NEXT technology validation. The NEXT project - at the completion of CY07-should be in a high state of technical readiness to support FY08 Announcement of Opportunities (AO) relative to Discovery- and New Frontier-class missions. Functional and qualification-level environmental testing of key system elements are scheduled to be completed; the thruster life test should exceed the throughput demonstrated on the NSTAR thruster; and system integration testing with the most mature hardware products will be drawing to a close. The project has identified a number of additional tasks to facilitate transition to first flight and these have been recommended to ISPT.

NEXT IPS technologies will be ready for upcoming competed and directed robotic mission opportunities in the FY08/09 timeframe. With additional investments in transitioning the technology to flight, NEXT IPS 1st-user costs should be about half that experienced with the Dawn mission IPS.

\section{References}

1. Benson, S., Patterson, M., Vaughan, D., Wilson, A., and Wong, B., "NASA's Evolutionary Xenon Thruster (NEXT) Phase 2 Development Status," AIAA-2005-4070, Joint Propulsion Conference, July 2005.

2. Patterson, M.J., Foster, J.E., Haag, T.W., Soulas, G.C., Pastel, M.R., and Roman, R.F., "NEXT: NASA'S Evolutionary Xenon Thruster Development Status," AIAA-2003-4862, Joint Propulsion Conference, July 2003.

3. Todd, P. Wiseman, S., Martinelli, R., and Pinero, L., "Status of the NEXT $7 \mathrm{~kW}$ Power Processing Unit," AIAA-2005-3868, Joint Propulsion Conference, July 2005.

4. Hoskins, W., Polaha, J., Hobson, D., Soulas, G., Patterson, M., Sovey, J., and Talerico, L., "Overview of the NEXT Ion Propulsion System Program at Aerojet," AIAA-2005-3885, Joint Propulsion Conference, July 2005.

5. Monheiser, J., Aadland, R., and Wilson, F., "Development of a Ground Based Digital Control Interface Unit (DCIU) for the NEXT Propulsion System," AIAA-2004-4112, Joint Propulsion Conference, July 2004.

\footnotetext{
${ }^{12}$ A NASA GRC/JPL jointly-developed cost model for the NEXT IPS estimates 1 st-user costs to be approximately $50 \%$ of the Dawn IPS.
} 
6. Brophy, J.R., et al., "Ion Propulsion System (NSTAR) DS1 Technology Validation Report," JPL Publication 00-10, October 2000.

7. Brophy, J.R., "Preliminary Dawn IPS Lessons Learned," JPL, September 9, 2005.

8. Soulas, G.C., Domonkos, M.T., and Patterson, M.J., "Performance Evaluation of the NEXT Ion Engine, AIAA-2003-5278, Joint Propulsion Conference, July 2003.

9. Soulas, G.C., et al., "NEXT Ion Engine 2000 Hour Wear Test Results," AIAA-2004-3791, Joint Propulsion Conference, July 2004.

10. Patterson, M.J., Pinero, L., Aadland, R., and Komm, D., "NEXT Ion Propulsion System: SingleString Integration Test Results," JANNAF Conference, May 2004.

11. Patterson, M.J., et al., "NEXT: NASA'S Evolutionary Xenon Thruster Development Status," AIAA2003-4862, Joint Propulsion Conference, July 2003.

12. Patterson, M.J., Foster, J., McEwen, H., Pencil, E., Van Noord, J., and Herman, D., "NEXT MultiThruster Array Test - Engineering Demonstration," AIAA-2006-5180, Joint Propulsion Conference, July 2006.

13. Aadland, R.S., Frederick, H., Benson, S.W., and Malone, S., "Development Results of the NEXT Propellant Management System," JANNAF Conference, 2005.

14. Brophy, J.R, et al., "Status of the Dawn Ion Propulsion System," AIAA-04-3433, Joint Propulsion Conference, July 2004.

15. Snyder, J.S, O’Connell, M.R., Fernandez, J.P., Wang, G., McNabb, R.S., and Crumb, D., "Vibration Test of a Breadboard Gimbal for the NEXT Ion Engine," AIAA Paper no. 2006-4665, Joint Propulsion Conference, July 2006.

16. Pencil, E.J., Foster, J.E., Patterson, M.J., Diaz, E., Van Noord, J., and McEwen, H., "Ion Beam Characterization of NEXT Multi-Thruster Array Plume," AIAA-2006-5182, Joint Propulsion Conference, July 2006.

17. Foster, J.E., Pencil, E., Patterson, M.J., McEwen, H., Diaz, E., and Van Noord, J., "Plasma Characteristics Measured in the Plume of a NEXT Multi-Thruster Array," AIAA-2006-5181, Joint Propulsion Conference, July 2006.

18. McEwen, H., Foster, J.E., Pencil, E., Patterson, M.J., Diaz, E., and Van Noord, J., "Characterization of Plasma Flux Incident on a Multi-Thruster Array," AIAA-2006-5183, Joint Propulsion Conference, July 2006.

19. Foster, J.E., Pencil, E., McEwen, H., Patterson, M.J., Diaz, E., and Van Noord, J., "Neutralizer Plasma Coupling in a NEXT Multi-thruster array," AIAA-2006-5184, Joint Propulsion Conference, July 2006.

20. Van Noord, J., "NASA's Evolutionary Xenon Thruster (NEXT) Ion Propulsion System - Technology for NASA Space Science Missions - Service Life Assessment," GRC-NEXT-103, December 21, 2005.

21. Patterson, M.J. "NEXT Study of Thruster Extended-Performance (NEXT STEP)," AIAA-20064664, Joint Propulsion Conference, July 2006. 


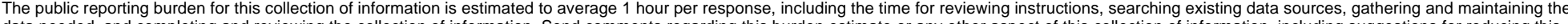

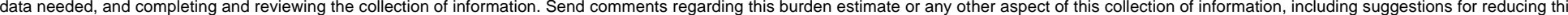

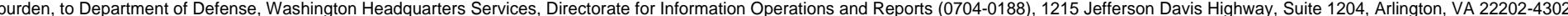

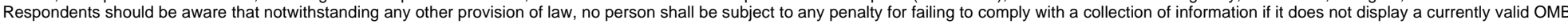
control number.

PLEASE DO NOT RETURN YOUR FORM TO THE ABOVE ADDRESS.

\section{REPORT DATE $(D D-M M-Y Y Y Y)$ \\ 2. REPORT TYPE \\ 3. DATES COVERED (From - To)}

01-01-2008

\section{TITLE AND SUBTITLE}

NEXT Ion Propulsion System Development Status and Performance

5b. GRANT NUMBER

5c. PROGRAM ELEMENT NUMBER

\section{AUTHOR(S)}

Patterson, Michael, J.; Benson, Scott, W.

\section{5d. PROJECT NUMBER}

5e. TASK NUMBER

5f. WORK UNIT NUMBER

WBS 346620.04.05.03.11

\section{PERFORMING ORGANIZATION}

REPORT NUMBER

E-16148

National Aeronautics and Space Administration

John H. Glenn Research Center at Lewis Field

Cleveland, Ohio 44135-3191

9. SPONSORING/MONITORING AGENCY NAME(S) AND ADDRESS(ES)

National Aeronautics and Space Administration

Washington, DC 20546-0001

\section{SPONSORING/MONITORS ACRONYM(S) \\ NASA \\ 11. SPONSORING/MONITORING REPORT NUMBER \\ NASA/TM-2008-214986; AIAA-2007- 5199}

\section{DISTRIBUTIONIAVAILABILITY STATEMENT}

Unclassified-Unlimited

Subject Category: 20

Available electronically at http://gltrs.grc.nasa.gov

This publication is available from the NASA Center for AeroSpace Information, 301-621-0390

\section{SUPPLEMENTARY NOTES}

\section{ABSTRACT}

NASA's Evolutionary Xenon Thruster (NEXT) project is developing next generation ion propulsion technologies to provide future NASA science missions with enhanced mission performance benefit at a low total development cost. The objective of the NEXT project is to advance next generation ion propulsion technology by producing engineering model and prototype model system components, validating these through qualification-level and integrated system testing, and ensuring preparedness for transitioning to flight system development. This paper describes the NEXT ion propulsion system development status, characteristics and performance. A review of mission analyses results conducted to date using the NEXT system is also provided.

15. SUBJECT TERMS

Propulsion; Electric propulsion; Electrostatic propulsion; Ion propulsion; Ion optics

\begin{tabular}{|c|c|c|c|}
\hline \multicolumn{3}{|c|}{ 16. SECURITY CLASSIFICATION OF: } & $\begin{array}{l}\text { 17. LIMITATION OF } \\
\text { ABSTRACT }\end{array}$ \\
\hline $\begin{array}{l}\text { a. REPORT } \\
\mathrm{U}\end{array}$ & $\begin{array}{l}\text { b. ABSTRACT } \\
U\end{array}$ & $\begin{array}{l}\text { c. THIS } \\
\text { PAGE } \\
\text { U }\end{array}$ & UU \\
\hline
\end{tabular}

18. NUMBER
OF
PAGES
24

19a. NAME OF RESPONSIBLE PERSON STI Help Desk (email:help@sti.nasa.gov) 19b. TELEPHONE NUMBER (include area code) 301-621-0390 

